\title{
Ultra-Trace Determination of Lead(II) in Water Using Electrothermal Atomic Absorption Spectrometry after Preconcentration by Solid-Phase Extraction to a Small Piece of Cellulose Acetate Type Membrane Filter
}

\author{
Hitoshi MizuguchI, ${ }^{* \dagger}$ Mirai Ishida, ${ }^{*}$ Tomohiro TaKahaShI,* Atsushi SaSAKI,** and Junichi ShIDA* \\ *Graduate School of Science and Engineering, Yamagata University, Yonezawa 992-8510, Japan \\ **Technical Division of Instrumental Analysis, Faculty of Engineering, Yamagata University, \\ Yonezawa 992-8510, Japan
}

\begin{abstract}
A simple and inexpensive preconcentration technique has been developed for the ultra-trace determination of lead(II) using electrothermal atomic absorption spectrometry (ETAAS). The lead(II) complex with dicyclohexano-18-crown 6-ether (DC18C6) was extracted to a small piece of cellulose acetate-type membrane filter $(2 \times 5 \mathrm{~mm})$ merely by vigorously eccentric stirring for $120 \mathrm{~min}$ under the coexistence of sodium dodecyl sulfate (SDS) at around $\mathrm{pH} 7$. The extraction medium was inserted into a graphite cuvette for the determination of lead(II) by ETAAS. A linear relation was obtained for the range of $0.1-5.0 \mathrm{ng}$ in $10 \mathrm{ml}$ of lead(II) standard solution $(r=0.998)$. The detection limit was found to be $0.03 \mathrm{ng}$ of lead(II) in $10 \mathrm{ml}\left(0.003 \mu \mathrm{g} \mathrm{l}^{-1}\right)$ of water sample. The proposed method was applied to the ultra-trace determination of lead(II) in river water, underground water, tap water, and snow fall samples.
\end{abstract}

(Received September 12, 2010; Accepted November 20, 2010; Published January 10, 2011)

\section{Introduction}

The determination of trace amounts of heavy metal ions, such as lead(II) in environmental samples, is of great importance because of their high toxicity and accumulative and persistent character in the environment and living organisms. ${ }^{1}$ Electrothermal atomic absorption spectrometry (ETAAS) is a powerful tool for the determination of heavy metal ions in different samples because of its excellent analytical performance, low cost of required instrumentation, high sensitivity, and selectivity. The determination of lead(II) at parts per trillion levels in natural water samples using ETAAS requires a preliminary separation and preconcentration step to eliminate the matrix components, and to improve the detection limits. Several preconcentration methods have been used for trace lead(II) determinations; these include co-precipitation, ${ }^{2,3}$ liquid-liquid extraction, ${ }^{4-7}$ solid-phase extraction (SPE), ${ }^{8-17}$ combination of co-precipitation and SPE, ${ }^{18}$ combination of liquid-liquid extraction and SPE, ${ }^{19}$ and cloud point extraction..$^{20}$ Research in this area has recently been reviewed; several different techniques have been outlined..$^{21,22}$

This study is intended to develop a simple and inexpensive preconcentration technique for the ultra-trace determination of lead(II) using ETAAS. Over the past decades, great effort has been expended towards the development of solid-phase extraction systems using membrane filters, which are very useful media for the preconcentrations of various analytical

$\dagger$ To whom correspondence should be addressed.

E-mail: mizu@yz.yamagata-u.ac.jp tools. ${ }^{9,23-31}$ Electrothermal atomic absorption spectrometry with the direct ashing of an extraction medium, such as membrane filters on which the analyte is concentrated, enables highly sensitive determination. ${ }^{26-31}$ The elimination of the elution (leaching) or dissolution step simplifies the analytical procedure and reduces any risks of contamination. A suspension of fine particles holding the analyte was also introduced directly into a graphite tube for determining the desired element; high enrichment factors were observed in the slurry injection techniques. ${ }^{32-36}$ Although the coupling of flow-injection on-line column preconcentration/separation techniques to ETAAS is effective for the simplifying the operation, ${ }^{21}$ the treatment of large volumes of aqueous samples is often time-consuming. These methods are unsuitable for processing many samples in a short time.

Macrocyclic crown ethers possessing the 18-crown 6-ether skeleton are known to exhibit specific interactions with lead(II). ${ }^{37,38}$ Numerous reports have described solvent extraction with the 18-crown 6-ether derivatives. ${ }^{39-41}$ A flow-injection on-line preconcentration system was also developed using a lead selective resin that was modified with an 18-crown 6-ether derivative, and a superior performance was obtained in the lead(II) determination using ETAAS. ${ }^{18}$ In this study, we describe a new preconcentration technique based on the ion-pair solid-phase extraction of lead(II) to a small piece of hydrophilic polymer membrane filter for ultra-trace determination. The lead(II) complex with dicyclohexano-18-crown 6-ether (DC18C6) was extracted to a cellulose acetate-type membrane filter $(2 \times 5 \mathrm{~mm})$ merely by vigorous eccentric stirring for 120 min under the coexistence of sodium dodecyl sulfate (SDS). The extraction medium was inserted into a graphite cuvette for 
Table 1 Temperature program of the graphite furnace

\begin{tabular}{ccccc}
\hline Step & $\begin{array}{c}\text { Temperature/ } \\
{ }^{\circ} \mathrm{C}\end{array}$ & Ramp/s & Hold/s & $\begin{array}{c}\text { Argon flow } \\
\text { rate/ml min }\end{array}$ \\
\hline 1 & $80-140$ & 40 & - & 30 \\
2 & 140 & - & 60 & 0 \\
3 & 600 & - & 40 & 200 \\
4 & 2400 & - & 5 & 30 \\
5 & 2700 & - & 4 & 200 \\
\hline
\end{tabular}

the determination of lead(II) using ETAAS. The detection limit was $0.003 \mu \mathrm{g} \mathrm{l}^{-1}$. The proposed method was applied to the ultra-trace determination of lead(II) in river water, underground water, tap water, and snow fall samples.

\section{Experimental}

\section{Materials}

The lead(II) standard solution, $1000 \mathrm{mg} \mathrm{l}^{-1}$, was from Kanto Chemical Co., Inc. (Tokyo, Japan), and intermediate solutions were prepared by appropriate dilution of the stock solution. The solution $(0.01 \mathrm{M})$ of the reagent, dicyclohexano-18-crown 6-ether (Merck KGaA, Darmstadt, Germany), was prepared by dissolving it in deionized water. The solution $(0.01 \mathrm{M})$ of sodium $n$-dodecyl sulfate (Tokyo Chemical Industry Co., Ltd., Tokyo, Japan) was prepared by dissolving it in deionized water. The $\mathrm{pH}$ buffer solutions used were $0.1 \mathrm{~mol} \mathrm{l}^{-1}$ sodium acetate- $\mathrm{HCl}$ (pH 4.0 - 6.0), $0.1 \mathrm{~mol} \mathrm{l}^{-1}$ 2-[4-(2-hydroxyethyl)1-piperazinyl]ethanesulfonic acid (HEPES)-NaOH (pH 6.8 - 8.2), and $\mathrm{N}$-cyclohexyl-2-aminoethanesulfonic acid (CHES) $-\mathrm{NaOH}$ (pH 9.0 - 10.0). Ultrapure grade nitric acid solution (60\%) was purchased from Kanto Chemical Co., Inc. (Japan). All other reagents were of analytical grade. Unless otherwise stated, all water was $18 \mathrm{M} \Omega \mathrm{cm}$ deionized water purified with an ultrapure water system (MINIPURE TW-300RU; Nomura Micro Science Co., Ltd., Japan). The small piece of hydrophilic polymer membrane filter was prepared as an extraction medium by cutting a cellulose acetate-type membrane filter (pore size $0.20 \mu \mathrm{m}$, Advantec Toyo Kaisha, Ltd., Japan) into a $2 \times 5 \mathrm{~mm}$ rectangle.

\section{Apparatus}

An atomic absorption spectrometer (Model Z-5010; Hitachi Ltd., Japan) with a polarized Zeeman-effect background corrector was used with a $\mathrm{Pb}$ hollow-cathode lamp (No. 208-2023; Hitachi). The lamp current, wavelength, and slit width were set, respectively, to $9.0 \mathrm{~mA}, 283.3 \mathrm{~nm}$, and $1.3 \mathrm{~nm}$. A tube-type pyrolytic graphite coated cuvette (No. 190-6003; Hitachi Ltd.) was used throughout this work. Argon gas $(>99.99 \%)$ was used as a sheath gas. A graphite furnace program for the determination of lead is given in Table 1. A drying process at $140^{\circ} \mathrm{C}$ for $60 \mathrm{~s}$ was added to a program recommended by the instrument manufacturer. This condition provided stable and sequential analyses, because no ash remained in the graphite cuvette. A direct mixer (Model DM-301; AS ONE Corp., Japan) was used for eccentric stirring of the sample solutions in perfluoroalkoxy (PFA) vials (No. 0275; Sanplatec Corp., Japan). The stirring speed was set at No. 2 (around $600 \mathrm{rpm}$ ).

\section{Typical procedure}

A $10-\mathrm{ml}$ portion of the sample solution containing $0.03-$

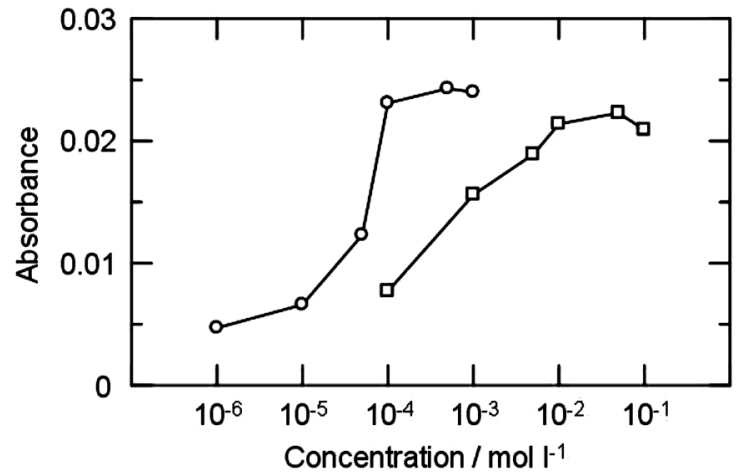

Fig. 1 Effect of the reagent concentration on the analytical signal. , DC18C6; $\square, 18 C 6$. Conditions: Pb(II), $0.10 \mu \mathrm{g} \mathrm{l}^{-1}$; SDS, $1.0 \times 10^{-4}$ mol 1-1; pH 7.0; stirring time, $30 \mathrm{~min}$; sample volume, $10 \mathrm{ml}$.

$5.0 \mathrm{ng}$ of lead(II) ion was taken in a PFA vial; then, $100 \mu \mathrm{l}$ of a DC18C6 solution, $100 \mu \mathrm{l}$ of an SDS solution, and $2 \mathrm{ml}$ of a $\mathrm{pH}$ buffer solution were added. Then a small piece of the cellulose acetate-type membrane filter was put into the mixture. After eccentric stirring for $120 \mathrm{~min}$ using a direct mixer, the mixture was poured into a Büchner funnel; a small piece of membrane filter was rinsed with $1 \mathrm{ml}$ of water. A graphite cuvette was taken out from the atomic absorption spectrometer; then the membrane filter was inserted into the cuvette using tweezers through a side hole, and the graphite cuvette was mounted on the spectrometer for determining the lead(II) content. A $10-\mu 1$ portion of nitric acid solution $(1+1)$ as a chemical modifier was added to the graphite cuvette through the upper hole before running the ETAAS program. The absorbance value was used exclusively for signal evaluation.

\section{Results and Discussion}

\section{SPE condition}

In this study, 18-crown 6-ether (18C6), dicyclohexano-18-crown 6-ether (DC18C6), and dibenzo-18-crown 6-ether (DB18C6) were tested for the solid-phase extraction with a small piece of cellulose acetate-type membrane filter. Stable ETAAS responses of lead(II) were obtained when $18 \mathrm{C} 6$ or DC18C6 was used for the solid-phase extraction, although the responses were not obtained with DB18C6. The effects of the reagent concentration in the solution are presented in Fig. 1. The ETAAS, respectively, responses in the presence of excess reagents, such as DC18C6 or 18C6, achieved maximum value and remained constant in concentration ranges greater than $1 \times 10^{-4}$ or $1 \times 10^{-2} \mathrm{~mol} \mathrm{l}^{-1}$, and the higher ETAAS responses were observed by using DC18C6. This probably reflects the higher hydrophobic nature of DC18C6 compared with 18C6. On the other hand, it is considered that the complex formation between lead(II) and DB18C6 is not quantitative in aqueous solution under this experimental condition because the water solubility of DB18C6 is extremely low. Therefore, DC18C6 was selected as an extraction reagent in this proposed method. The effect of the $\mathrm{pH}$ on the solid-phase extraction of $0.10 \mu \mathrm{g} \mathrm{l}^{-1}$ of lead(II) is presented in Fig. 2. The highest ETAAS response was obtained at around $\mathrm{pH}$ 7. The effects of the amount of SDS are depicted in Fig. 3. The highest and almost constant signal was obtained in ETAAS measurements when greater than $1 \times 10^{-4} \mathrm{~mol} \mathrm{l}^{-1}$ was added. Figure 4 shows the effects of the stirring time after adding the SDS solution. The ETAAS response achieved 


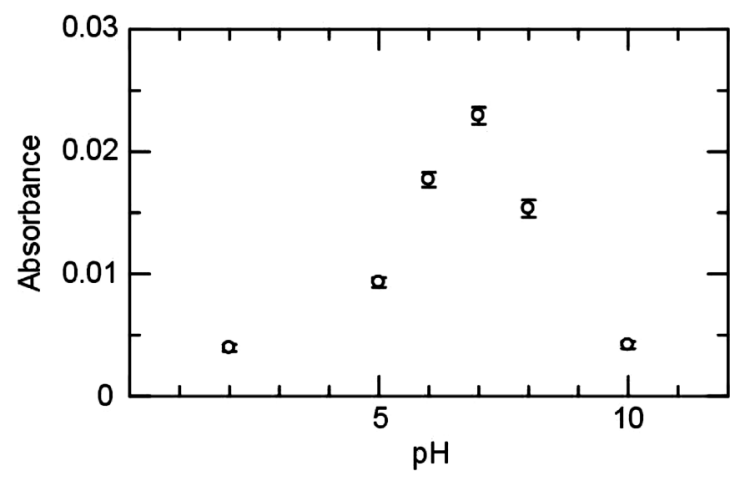

Fig. 2 Effect of the sample solution $\mathrm{pH}$ on the analytical signal. Conditions: $\mathrm{Pb}(\mathrm{II}), 0.10 \mu \mathrm{g} \mathrm{l} \mathrm{H}^{-1}$; DC18C6, $1.0 \times 10^{-4} \mathrm{~mol} \mathrm{l}^{-1}$; SDS, $1.0 \times 10^{-4} \mathrm{~mol} \mathrm{l}^{-1}$; stirring time, $30 \mathrm{~min}$; sample volume, $10 \mathrm{ml}$. The error bar indicates the standard deviation with three replicate measurements.

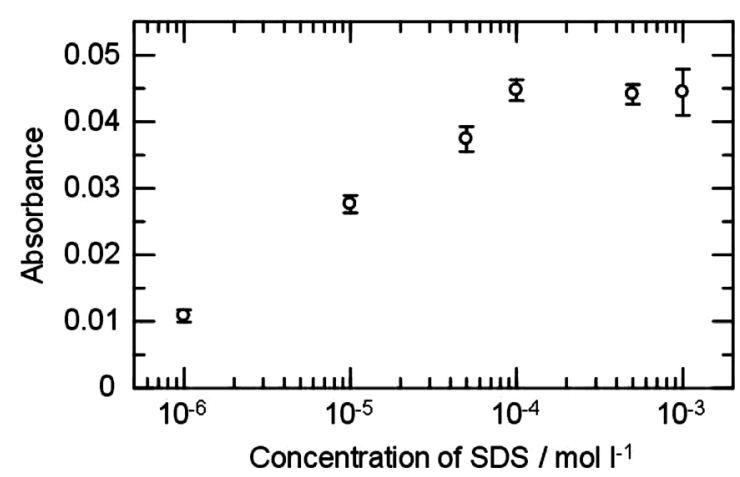

Fig. 3 Effect of the concentration of SDS on the analytical signal. Conditions: $\mathrm{Pb}$ (II), $0.10 \mu \mathrm{g} \mathrm{l^{-1 }}$; DC18C6, $1.0 \times 10^{-4} \mathrm{~mol} \mathrm{l}^{-1} ; \mathrm{pH} 7.0$; stirring time, $120 \mathrm{~min}$; sample volume, $10 \mathrm{ml}$. The error bar indicates the standard deviation with three replicate measurements.

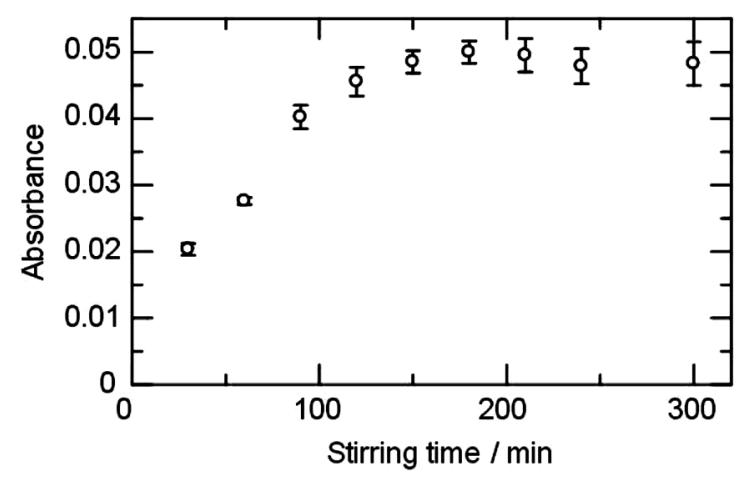

Fig. 4 Effect of the stirring time on the analytical signal. Conditions: $\mathrm{Pb}$ (II), $0.10 \mu \mathrm{g} \mathrm{l}^{-1} ; \quad$ DC18C6, $1.0 \times 10^{-4} \mathrm{~mol} \mathrm{l}^{-1} ; \quad$ SDS, $1.0 \times 10^{-4}$ mol 1-1; $\mathrm{pH} 7.0$; sample volume, $10 \mathrm{ml}$. The error bar indicates the standard deviation with three replicate measurements.

maximum, and maintained a constant value after $120 \mathrm{~min}$. The proposed preconcentration method is based on ion-pair solid-phase extraction. Dodecyl sulfate ion, which is negatively charged, behaves mainly as a counter anion for the extraction of the lead(II)-DC18C6 complex. However, the mechanism seems to be more complicated, considering the effect of the $\mathrm{pH}$ and the
Table 2 Extraction efficiency of the proposed SPE technique

\begin{tabular}{ccc}
\hline Temperature $/{ }^{\circ} \mathrm{C}$ & $\begin{array}{c}\text { Absolute } \\
\text { amount/ng }\end{array}$ & $\begin{array}{c}\text { Extraction } \\
\text { efficiency, \% }\end{array}$ \\
\hline \multirow{2}{*}{15.8} & 0.20 & 19.9 \\
& 0.40 & 21.5 \\
20.5 & 1.0 & 22.0 \\
& 0.20 & 23.1 \\
& 0.40 & 24.2 \\
1.0 & 24.8 \\
\hline
\end{tabular}

required concentration of SDS. Although the details still remain to be investigated, the important parameters for the reproducibility of analyses are a sufficiently large amount of SDS and a $\mathrm{pH}$ control. Based on these data, a $\mathrm{pH}$ value of 7.0, an SDS concentration of $1 \times 10^{-4} \mathrm{~mol} \mathrm{l}^{-1}$, and a stirring time of 120 min were adopted as the optimum SPE condition.

\section{Extraction efficiency}

In this study, the extraction efficiency $(N)$ was defined by the following expression:

$$
N(\%)=\frac{I_{\mathrm{a}}-I_{0}}{I_{\mathrm{b}}-I_{0}^{\prime}} \times 100 .
$$

In that equation, $I_{\mathrm{a}}$ and $I_{0}$, respectively, represent the absorbance value obtained according to the typical procedure and the background signal $(=0.004)$. Also, $I_{\mathrm{b}}$ denotes the absorbance value obtained by adding a $20-\mu 1$ of aqueous solution containing the same absolute amount of lead(II) to the pyro cuvette, into which a small piece of cellulose acetate-type membrane filter has been inserted beforehand. As shown in Table 2, the extraction efficiency was $23-25 \%$ at $20^{\circ} \mathrm{C}$. Although the extraction efficiency tends to be higher according to the increase of temperature, measurements with a good reproducibility are possible at constant room temperature. However, the extraction efficiency decreased as the sample volume increased. When the sample volume was $100 \mathrm{ml}$, the extraction efficiency was around $5 \%$. The extraction efficiency also tended to be lower according to an increase of pore sizes. When the membrane filter with a pore size of $0.45 \mu \mathrm{m}$ was used, the extraction efficiency decreased by $12 \%$ compared with the value obtained by using the membrane filter with a pore size of $0.20 \mu \mathrm{m}$. As a result, the membrane filter with a pore size of $0.20 \mu \mathrm{m}$, which was the minimum size in the market, was used for this study.

\section{Calibration curve and detection limit}

A linear relation through the point of origin between the absorbance and the concentration was obtained for the range of $0.1-5.0 \mathrm{ng}$ in $10 \mathrm{ml}$ of lead(II) standard solution $(A=0.044 C+$ $0.0016, r=0.998)$. The average value and standard deviation of the blank signals were 0.0039 and 0.0004 , respectively. The detection limit, defined as three-times the standard deviation of the reagent blank, was $0.03 \mathrm{ng}$ of lead(II) in $10 \mathrm{ml}\left(0.003 \mu \mathrm{g} \mathrm{l}^{-1}\right)$ of the water sample. The precision (RSD) for ten replicate measurements of $0.1 \mathrm{ng}$ of $\mathrm{Pb}\left(0.010 \mu \mathrm{g} \mathrm{l}^{-1}\right)$ was $7.0 \%$. The enhancement factor obtained by the slope ratio of the two calibration curves with preconcentration and without preconcentration was 76. A comparison of the proposed method with the other reported preconcentration methods for the ultra-trace determination of lead(II) is given in Table 3. As can be seen, this proposed method, which is easy to operate without any organic solvents harmful to the human body, presents a low 
Table 3 Characteristic performance data obtained by ETAAS equipped with preconcentration techniques for the ultra-trace determination of lead(II)

\begin{tabular}{|c|c|c|c|c|c|}
\hline Preconcentration method & $\mathrm{LOD}^{\mathrm{a}} / \mu \mathrm{g} \mathrm{1^{-1 }}$ & Sample volume/ml & Linear range $/ \mu g 1^{-1}$ & $\mathrm{CF}^{\mathrm{b}}$ & Ref. \\
\hline Slurry injection after coprecipitation & 0.0015 & 50 & - & 100 & 3 \\
\hline Dispersive liquid-liquid microextraction & 0.02 & 5 & $0.05-1$ & 150 & 7 \\
\hline SPE with a miniature-membrane filter by filtration & 0.01 & 10 & - & 50 & 9 \\
\hline On-line SPE with a flow injection system & 0.002 & 2 & $0.01-1.5$ & 23 & 8,11 \\
\hline Off-line SPE with a column packed with an absorbent & 0.051 & 100 & $0-20$ & 100 & 17 \\
\hline Cloud point extraction & 0.08 & 10 & Up to 30 & $50^{\mathrm{c}}$ & 20 \\
\hline SPE with a small piece of membrane filter by eccentric stirring & 0.003 & 10 & $0.010-0.5$ & $76^{\mathrm{d}}$ & This work \\
\hline
\end{tabular}

a. Limit of detection. b. Concentration factor. c. Enhancement factor calculated as the ratio of absorbance of preconcentration samples to that obtained without preconcentration. d. Enhancement factor calculated by comparing with direct injection of $20 \mu l$ aqueous solution.

Table 4 Effect of foreign ions

\begin{tabular}{|c|c|c|c|}
\hline Substance & Added as & $\begin{array}{l}\text { Tolerated limit } \\
\text { (molar ratio) }\end{array}$ & Recovery, $\%$ \\
\hline Sodium & $\mathrm{NaCl}$ & $1 \times 10^{9 a}$ & 95 \\
\hline Potassium & $\mathrm{K}_{2} \mathrm{SO}_{4}$ & $1 \times 10^{8 \mathrm{a}}$ & 96 \\
\hline Magnesium & $\mathrm{Mg}\left(\mathrm{NO}_{3}\right)_{2}$ & $1 \times 10^{8 \mathrm{a}}$ & 95 \\
\hline Calcium & $\mathrm{CaCl}_{2}$ & $1 \times 10^{8 a}$ & 101 \\
\hline Zinc & Nitric acid solution & $1 \times 10^{5}$ & 98 \\
\hline Manganese & $\mathrm{MnSO}_{4}$ & $1 \times 10^{5}$ & 95 \\
\hline Copper & $\mathrm{CuCl}_{2}$ & $1 \times 10^{5}$ & 103 \\
\hline Cadmium & Nitric acid solution & $1 \times 10^{5}$ & 105 \\
\hline Chromium & $\mathrm{CrCl}_{3}$ & $1 \times 10^{5}$ & 96 \\
\hline \multirow[t]{3}{*}{ Iron } & $\mathrm{FeCl}_{3}$ & $1 \times 10^{5}$ & 90 \\
\hline & & $1 \times 10^{6}$ & 70 \\
\hline & & $1 \times 10^{6}$ & $95^{\mathrm{b}}$ \\
\hline Fluoride & $\mathrm{NaF}$ & $1 \times 10^{6}$ & 103 \\
\hline
\end{tabular}

Pb taken: $4.8 \times 10^{-10} \mathrm{~mol} \mathrm{l}^{-1}$.

a. The maximum value tested in this study.

b. With sodium fluoride.

detection limit, a superior enhancement factor, and relatively low sample consumption.

\section{Effect of foreign ions}

The effects of commonly occurring foreign ions on the determination of $1.0 \mathrm{ng}$ of lead(II) in $10 \mathrm{ml}\left(4.8 \times 10^{-10} \mathrm{~mol} \mathrm{l}^{-1}\right)$ are presented in Table 4 . A given species was considered to interfere if it caused a $\pm 5 \%$ variation of the ETAAS signal. Most ions did not interfere with the determination of lead(II). Especially, the proposed method has a superior salinity tolerance. For sodium, potassium, magnesium and calcium, each tolerated limit of these ions is equivalent to the concentrations in the majority of seawater. Although a large amount of iron(III) will cause a negative error, this interference can be eliminated by adding $100 \mu \mathrm{l}$ of a $0.01 \mathrm{M} \mathrm{NaF}$ solution. It is well-known that parts-per-million levels of iron and manganese are often contained in underground water. The results listed in Table 4 show that the proposed method also has a sufficient tolerance to these metal ions. Therefore, the proposed method has superior selectivity, and is suitable for the determination of lead(II) in not only drinking water, but also various natural water samples.

\section{Applications}

To evaluate the usefulness of the proposed method, it was applied to an analysis of lead(II) from river water, snow fall, tap water, and underground water samples. The river-water sample was a standard reference material (NMIJ CRM 7201-a; National Institute of Advanced Industrial Science and Technology, Japan).
Table 5 Analytical results of water samples

\begin{tabular}{clcc}
\hline \multirow{2}{*}{ Sample } & \multicolumn{2}{c}{$\mathrm{Pb}(\mathrm{II})$ concentration $/ \mu \mathrm{g} \mathrm{l^{-1 }}$} & \\
\cline { 2 - 3 } & Added & Found $^{\mathrm{a}}$ & \\
\cline { 2 - 3 } River water $^{\mathrm{b}}$ & 0 & $0.0066 \pm 0.0015$ & - \\
& 0.010 & $0.017 \pm 0.002$ & 102 \\
Snowfall A & 0.020 & $0.025 \pm 0.002$ & 94 \\
pH 5.6 & 0 & $0.027 \pm 0.004$ & - \\
EC 110 & 0.010 & $0.039 \pm 0.005$ & 105 \\
Snowfall B & 0.020 & $0.043 \pm 0.005$ & 92 \\
pH 5.0 & 0 & $0.051 \pm 0.006$ & - \\
EC 330 & 0.010 & $0.060 \pm 0.008$ & 98 \\
Tap water A & 0.020 & $0.067 \pm 0.008$ & 94 \\
pH 6.9 & 0 & $0.15 \pm 0.01$ & - \\
EC 120 & 0.10 & $0.26 \pm 0.03$ & 104 \\
Tap water B & 0.20 & $0.31 \pm 0.05$ & 91 \\
pH 6.7 & 0 & $0.11 \pm 0.01$ & - \\
EC 130 & 0.10 & $0.20 \pm 0.03$ & 95 \\
Underground water $^{c}$ & 0.20 & $0.29 \pm 0.03$ & 94 \\
pH 6.6 & 0 & $2.1 \pm 0.1$ & - \\
EC 190 & 1.0 & $3.0 \pm 0.3$ & 97 \\
\hline
\end{tabular}

a. Average value of five replicate analyses.

b. The reference material (NMIJ CRM 7201-a), certified value is $0.0063 \pm 0.0008 \mu \mathrm{g} / \mathrm{kg}$.

c. EC: electric conductivity $\left(\mu \mathrm{S} \mathrm{cm}^{-1}\right)$.

The determination of lead(II) in the river-water sample was performed as noted in the typical procedure with no pretreatment. Fresh snow samples were taken in Yonezawa Campus, Yamagata University, Yonezawa, and thawed in our laboratory. The tap water and underground water were taken from an urban area of Yonezawa city. These samples were then filtered through a membrane filter of $0.45 \mu \mathrm{m}$ pore size, and acidified with $60 \%$ nitric acid to $\mathrm{pH} 2$ for storage. The underground water was diluted ten times before analysis. Unless otherwise stated, the concentrations of lead(II) were determined according to the typical procedure. The obtained results as well as the recovery tests portrayed in Table 5 indicate the suitability of the proposed method for the ultra-trace determination of lead(II) in water samples.

\section{Conclusions}

A simple and inexpensive preconcentration technique for the ultra-trace determination of lead(II) by ETAAS was demonstrated using a small piece of cellulose acetate-type membrane filter as 
an extraction medium. The handling of the extraction medium is simple, and this proposed procedure requires only $10 \mathrm{ml}$ of the sample solution. The SPE process can be performed merely by eccentric stirring. Furthermore, the simultaneous processing of many samples is possible using a direct mixer in which many vials can be set. We believe that this proposed method is useful for the management of water quality.

\section{Acknowledgements}

We express appreciation to Mr. Hideyuki Sakamoto and Mr. Akira Yonetani (Hitachi High-Technologies Corporation) for helpful discussions.

\section{References}

1. S. K. Hall, Environ. Sci. Technol., 1972, 6, 30.

2. V. Umashankar, R. Radhamani, K. Ramadoss, and D. S. R. Murty, Talanta, 2002, 57, 1029.

3. A. Baysal, S. Akman, and F. Calisir, J. Hazard. Mater., 2008, 158, 454.

4. K. Ndung'u, R. P. Franks, K. W. Bruland, and A. R. Flegal, Anal. Chim. Acta, 2003, 481, 127.

5. H. Jiang and B. Hu, Microchim. Acta, 2008, 161, 101.

6. H. F. Maltez, D. L. G. Borges, E. Carasek, B. Weltz, and A. J. Curtis, Talanta, 2008, 74, 800.

7. M. T. Naseri, M. R. M. Hosseini, Y. Assadi, and A. Kiani, Talanta, 2008, 75, 56.

8. M. Sperling, X.-P. Yan, and B. Welz, Spectrochim. Acta, Part B, 1996, 51, 1875.

9. M. Oshima, T. Ohsaki, and S. Motomizu, Bunseki Kagaku, 1998, 47, 513 .

10. E. Hosten and B. Welz, Anal. Chim. Acta, 1999, 392, 55.

11. X.-P. Yan, M. Sperling, and B. Welz, J. Anal. At. Spectrom., 1999, 14, 1625.

12. J. Nan, Y. Jiang, and X.-P. Yan, J. Anal. At. Spectrom., 2003, 18, 946.

13. Y.-H. Sung and S.-D. Huang, Anal. Chim. Acta, 2003, 495, 165.

14. S. Xingguang, W. Meijia, Z. Yihua, Z. Jiahua, Z. Hanqi, and J. Qinhan, Talanta, 2003, 59, 989.

15. E. Vereda Alonso, M. T. Siles Cordero, A. García de Torres, and J. M. Cano Pavón, Anal. Bioanal. Chem., 2006, 385, 1178 .

16. F. Bai and Z. Fan, Microchim. Acta, 2007, 159, 235.

17. J. K. Kiptoo, J. C. Ngila, and N. D. Silavwe, Microchim.
Acta, 2008, 160, 211.

18. J. Nakajima, Y. Hirano, and K. Oguma, Anal. Sci., 2003, 19,585

19. R. E. Sturgeon, S. S. Berman, A. Desaulniers, and D. S. Russell, Talanta, 1980, 27, 85.

20. J. Chen, S. Xiao, X. Wu, K. Fang, and W. Liu, Talanta, 2005, 67, 992.

21. K. Oguma, J. Flow Injection Anal., 2005, 22, 110.

22. M. das G. A. Korn, J. B. de Andrade, D. S. de Jesus, V. A. Lemos, M. L. S. F. Bandeira, W. N. L. dos Santos, M. A. Bezerra, F. A. C. Amorim, A. S. Souza, and S. L. C. Ferreira, Talanta, 2006, 69, 16

23. S. Taguchi, I. Kasahara, and N. Hata, Bunseki Kagaku, 1995, 44, 505.

24. S. Taguchi, H.-F. Sun, N. Hata, and I. Kasahara, Bunseki Kagaku, 2000, 49, 941

25. S. Taguchi and K. Murai, Bunseki, 2008, 67.

26. J. Shida, J. Mochizuki, and S. Matsuzaki, Bunseki Kagaku, 1994, 43, 1197.

27. J. Ito, M. Komata, and J. P. Susant, Bunseki Kagaku, 1996, 45,789

28. J. Ito, M. Komata, and Y. Kondou, Bunseki Kagaku, 1996, 45,859

29. J. Shida and S. Matsuzaki, Anal. Sci., 1997, 13, 41.

30. J. Shida and S. Umeki, Anal. Sci., 1999, 15, 1033.

31. J. Shida and S. Umeki, Bunseki Kagaku, 2001, 50, 143.

32. K. Ohzeki, M. Minorikawa, F. Yokota, I. Nukatsuka, and R. Ishida, Analyst, 1990, 115, 23.

33. R. Horiguchi, I. Nukatsuka, Y. Shimizu, S. Sekikawa, and K. Ohzeki, Bunseki Kagaku, 2002, 51, 675.

34. I. Nukatsuka, Y. Shimizu, and K. Ohzeki, Anal. Sci., 2002 18,1009 .

35. I. Nukatsuka, H. Seitoh, and K. Ohzeki, Microchim. Acta, 2004, 148, 177.

36. A. Baysal, N. Tokman, S. Akman, and C. Ozeroglu, J. Hazard. Mater., 2008, 150, 804.

37. J. D. Lamb, R. M. Izatt, P. A. Robertson, and J. J. Christensen, J. Am. Chem. Soc., 1980, 102, 2452.

38. T. Hayashita, H. Sawano, T. Higuchi, M. Indo, K. Hiratani, Z.-Y. Zhang, and R. A. Bartsch, Anal. Chem., 1999, 71, 791.

39. T. Sekine, K. Shioda, and Y. Hasegawa, J. Inorg. Nucl. Chem., 1979, 41, 571.

40. Y. Takeda and H. Kato, Bull. Chem. Soc. Jpn., 1979, 52, 1027.

41. A. Sanz-Medel, D. B. Gomis, E. Fuente, and S. A. Jimeno, Talanta, 1984, 31, 515. 